\title{
Preliminary results of using ESR to examine biofilms
}

\author{
Neil Evan Whitehead ${ }^{*}$ \\ Department of Earth and Space Science \\ Graduate School of Science \\ Osaka University \\ 1-1 Machikaneyama, Toyonaka \\ Osaka 560-0043, Japan \\ E-mail:whiteh@paradise.net.nz \\ Tani Atushi \\ Department of Earth and Space Science \\ Graduate School of Science \\ Osaka University \\ 1-1 Machikaneyama, Toyonaka \\ Osaka 560-0043, Japan \\ Tel: 81668505491 \\ E-mail: atani@ess.sci.osaka-u.ac.jp \\ Kazue Tazaki \\ Department of Earth Sciences \\ Faculty of Science \\ Kanazawa University \\ Kakuma-machi, Kanazawa 920-1192, Japan \\ Tel: 82762645736 \\ E-mail: kazuet@kenroku.kanazawa-u.ac.jp \\ Motoji Ikeya \\ Department of Earth and Space Science \\ Graduate School of Science \\ Osaka University \\ 1-1 Machikaneyama, Toyonaka \\ Osaka 560-0043, Japan \\ Tel: 810668798492 \\ E-mail: ikeya35@sanken.osaka-u.ac.jp
}

Financial support: Senior Fellowship from the Japanese Society for the Promotion of Science.

Keywords: $\beta$-Biofilms, ESR, ferrihydrite, hematite, magnetite.

Present address: \#54 Redvers Drive, Lower Hutt, New Zealand 6009. Tel: 6445650263.

This preliminary work shows ESR (Electron Spin Resonance) can be used to detect biofilms, particularly from Fe-metabolising bacteria. A film was detected by ESR as early as 1 day, hence possibly more sensitively than by fluorescent methods. Films can probably be detected as early as one hour. Spectra contain a very broad peak at $\mathrm{g}=\mathbf{2 . 1 3}$, probably due to ferrihydrite. Results of field experiments from streams and ponds in New Zealand and Japan, particularly the Minoh River, showed a general increase of ferrihydrite with time. Loss by exfoliation was later than 20 days. The rate of accumulation was faster in a nutrient-rich stagnant pond. Hematite $(\mathrm{g}=4.3)$ was often observed, magnetite ( $g=9)$ once, and usually small amounts of a common bacterial decay product. The latter was detected for at least 18 months film storage. ESR is a particularly good tool for observing the growth of oxic biofilms containing
Fe-metabolising bacteria, and should be just as sensitive for observing Mn-metabolising bacteria in reducing conditions.

Biofilms form everywhere in rivers and lakes. In the Minoh River, Osaka, Japan, they biodegrade various aromatic hydrocarbons and remove pollution (Yamaguchi et al. 1997). They also form part of some Japanese sewage treatment systems (Okabe et al. 1997), and are studied to understand how to avoid the deposits of iron oxy-hydroxide (ferrihydrite) they form in water supplies (Tazaki et al. 2002). Electron Spin Resonance should be a useful tool to examine their growth, but we can find no previous record of this. The method is non destructive and samples can be re-measured if this is needed.

Peaks in ESR (which have an alternating-current shape) are described using " $\mathrm{g}$ - values" which are a measure of the

*Corresponding author 
Table 1. GPS locations of sample sites.

\begin{tabular}{|l|c|c|}
\hline & North Location & East Location \\
\hline Minoh R. Tributary & $34^{\circ} 50.532^{\prime}$ & $135^{\circ} 28.491^{\prime}$ \\
\hline Minoh R. Park & $34^{\circ} 49.436^{\prime}$ & $135^{\circ} 28.034^{\prime}$ \\
\hline Kanazawa University & $36^{\circ} 32.790^{\prime}$ & $136^{\circ} 42.612^{\prime}$ \\
\hline Int. House Pond, Osaka & $34^{\circ} 48.079^{\prime}$ & $135^{\circ} 27.538^{\prime}$ \\
\hline GNS, Lower Hutt, NZ & $41^{\circ} 14.114^{\prime}(\mathrm{S})$ & $174^{\circ} 55.231^{\prime}$ \\
\hline
\end{tabular}

magnetic fields at which they occur (i.e. cross the baseline). Thus a single peak actually has a positive and negative "peak". As reported (Swartz et al. 1972) many biota except biofilms, have been examined via ESR. Usually present are $\mathrm{Fe}^{3+}, \mathrm{Mn}^{2+}$ and organic radicals, the latter often due to lipid peroxidation in air, giving a signal at $\mathrm{g}=2.0055$. Bacteria give an additional signal at $\mathrm{g}=2.0035$, also due to bacterial membrane decay.

This work tried to examine some of the potential and limitations of the method using biofilms from streams and ponds in New Zealand and Japan.

\section{Materials and Methods}

Samples were mostly collected 2002-2003, either autumn or spring. The first samples were from streams in Lower Hutt, near Wellington, New Zealand, (mainly on the property of the Institute of Geological and Nuclear Science, abbreviation: "GNS"). The second collection were from locations near Osaka in Japan (Table 1 and Figure 1). The third collection were from Kanazawa University (Japan), $200 \mathrm{~km}$ north of Osaka. All sample sites were about pH 7, and oxic.

There were three Osaka locations, two on the Minoh River as shown in Figure 1. The first Osaka sample site was on a tributary of the Minoh River in its Quasi-National Park. This was at the north edge of Osaka, had low human impact and is called here "Minoh R. tributary" site. The second was from an apparently unpolluted spot in Minoh City downstream on Minoh river at a second park ("Minoh R. park" site).

In the Minoh River the majority bacterial genus was Flavobacterium, particularly the johnsonae species (Kenzaka et al. 1998). There were $16-17 \times 10^{5}$ cells $/ \mathrm{ml}$ as in the largest rivers through Osaka, though the Minoh River appears visually much less polluted. Depending on sample, $2.7-6.4 \%$ of the cells were respiring and $67-70 \%$ of the cells still had intact membranes (Yokomaku et al. 2000).

The third Osaka sample site was the International House Pond site (ca 1 hectare) adjacent to the Toyonaka Campus of Osaka University. It had a through-flow of much less than $1 \%$ per minute. It was nutrient-rich, cloudy with algae, and stocked with biota including fish, turtles, aquatic birds, and reeds, but further details are not yet available.

The Kanazawa location was flowing ground water on Kanazawa University property. A sample of biofilm and water was collected in 2001 and stored in a sealed container. Possibly growth had continued for some time after collection. There was a visible layer of film which easily peeled off the transparent walls of the container.
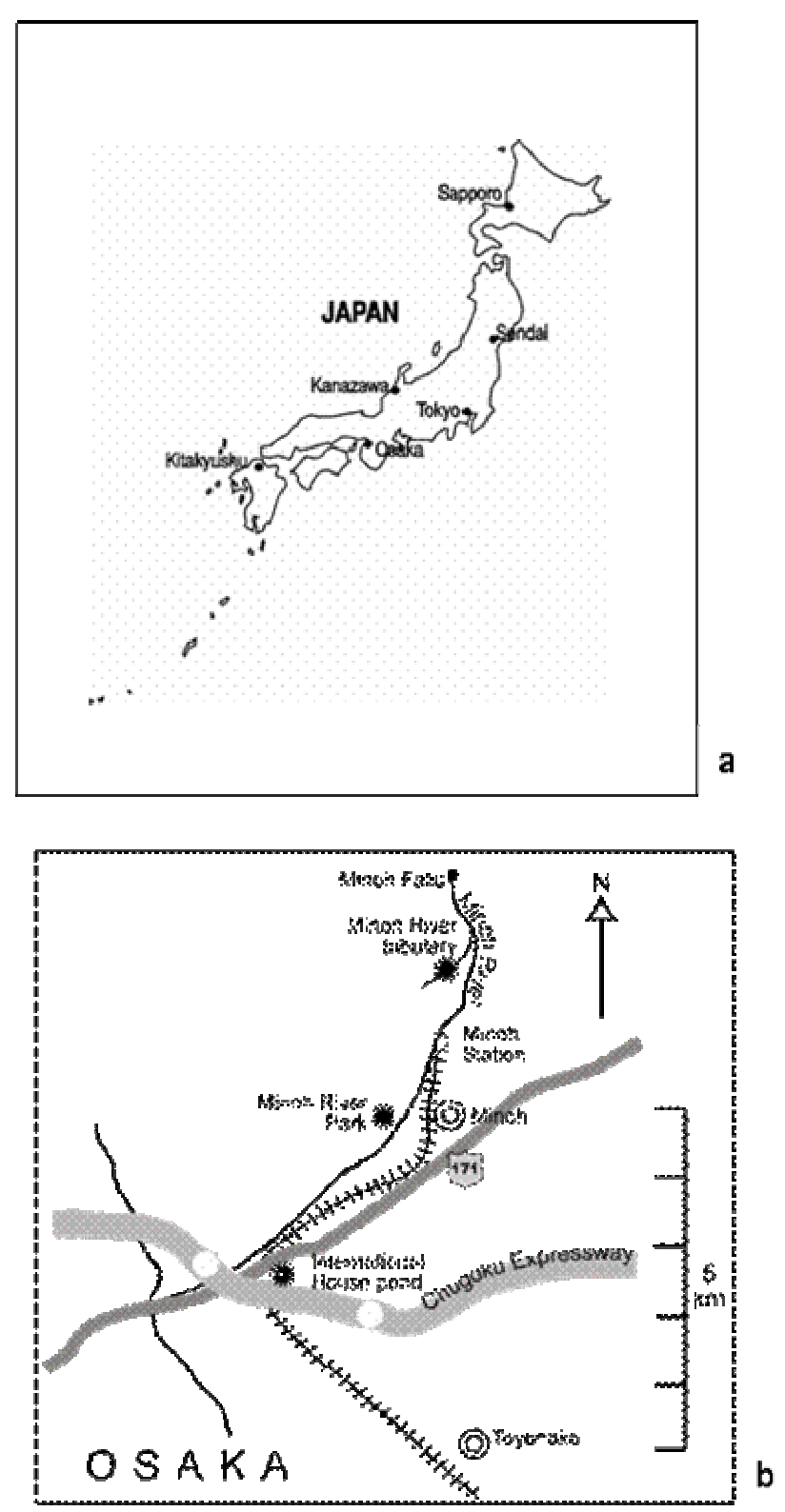

Figures 1a and 1b. Location maps for Japanese sampling sites.

Research on biofilms and corrosion frequently involves metal surfaces but macro amounts of metal interfere with the ESR measurement so metal substrates were avoided. 


\section{Dried Filtrate}

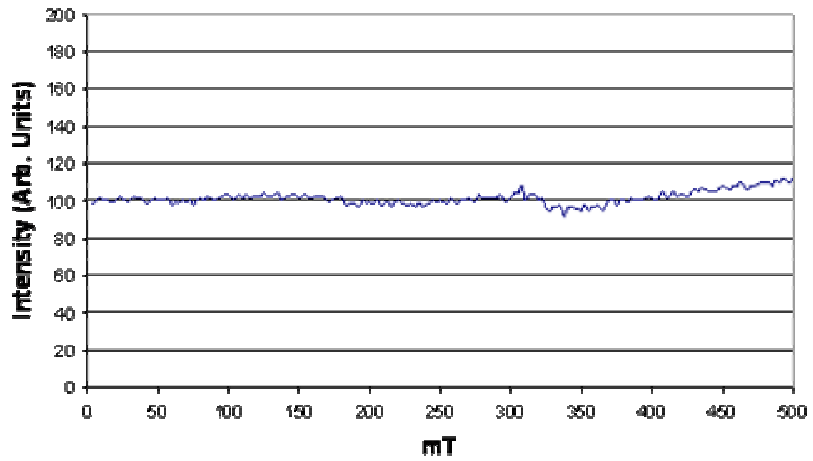

Figure 2. ESR spectrum of dried river-water filtrate.

Rate of growth of biofilm depends on the underlying substrate (Taylor et al. 1997). Tests in the Kanzaki River in Osaka, (Araya et al. 2003) showed that glass was the best substrate, stone and ceramic were second equal, and polycarbonate was third. Silica tubes are the usual sample containers in ESR measurements, and could be an approximation of glass. It would be possible to expose one to flowing stream water and later measure its ESR spectrum. This would be a useful model for film formation on fresh rock surfaces. However the ESR tubes were relatively expensive. Two researchers (Tokunaga and Morikawa, 2000) used unglazed tiles, which also would model rock surfaces.

Plastic film was a better choice: it was cheap and flexible, and had been used by others (Morikawa, 1988), but in some studies (Taylor et al. 1997) rates of growth depended on how hydrophilic the film was. The more hydrophilic the film the better the growth. We wondered if it were possible to make a hydrophobic film more hydrophilic and found this is already a common industrial process. It is common because commercial manufacturers want to print labels and logos on plastic surfaces, but find that normal hydrophilic surfaces cannot be wet properly with printers' ink. To make the surfaces receptive to ink, they are modified by flames or plasmas under carefully controlled conditions which very slightly oxidise the surfaces. We therefore used the clear plastic part of a partially printed polypropylene commercial bread bag. It had a very low ESR Background signal and biofilm grew well on it.

In contrast, Teflon (Polytetrafluorethylene) tape is extremely hydrophobic (though it also has a very low ESR background) and we compared growth rates of biofilms on polypropylene and Teflon in test locations, expecting much less biofilm growth on the Teflon.

Plastic strips were suspended from plastic-coated wire frames in local streams or ponds, by iron bulldog-type clips for up to several weeks. Samples were cut off the plastic at appropriate times and dried in air at ambient temperature overnight. Strips $1.5 \times 4 \mathrm{~cm}$ were rolled into a small cylinder, fastened with PTFE tape, and put vertically into the $7 \mathrm{~mm}$ i.d. ESR silica sample tube.

Spectra were taken with a conventional X-band ESR spectrometer (JEOL JES-RE1X) at room temperature (or with a $\mathrm{LN}_{2}$ cooled accessory as low as $-150^{\circ} \mathrm{C}$ ) with magnetic field usually $250 \pm 250 \mathrm{mT}$, magnetic field modulation $100 \mathrm{kHz}$ and other conditions as appropriate. For time-series work, the integrated area under peaks was measured using graphs from a chart recorder.

NZ GNS Biofilm

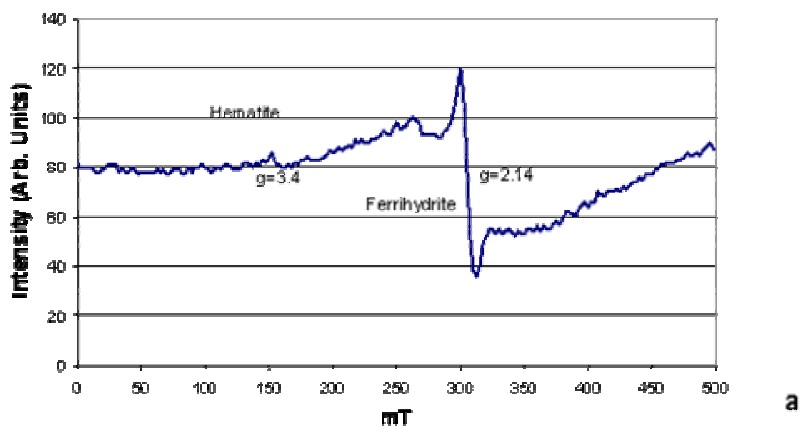

Minoh R. Tributary Biofilm

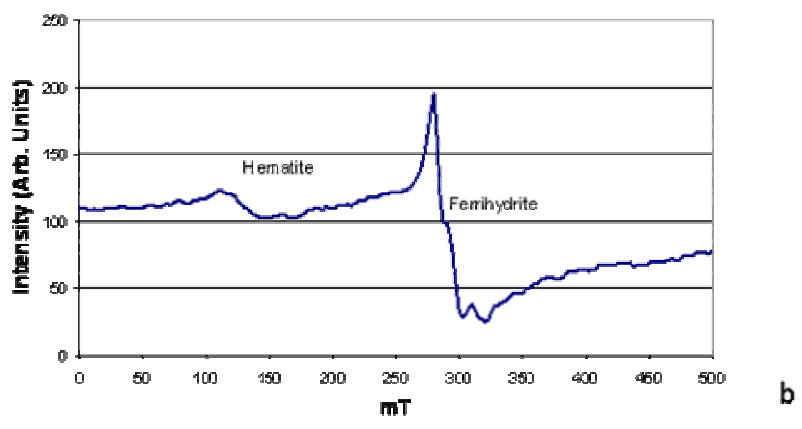

Figure 3a. Biofilm, 26 hours growth.

Figure 3b. Biofilm, 7 days growth

Five litres of NZ stream water were filtered with a paper filter to remove coarse debris. The solids in the filtrate were dried at room temperature and put in the ESR silica sample tube. This sample should represent bacteria floating in the river rather than attached biofilm.

Gamma irradiation often creates new informative ESR peaks in samples. For this we used the ${ }^{60} \mathrm{Co}$ facility of the Institute of Scientific and Industrial research on Osaka University campus.

\section{RESULTS}

The dried filtrate material gave almost no ESR spectrum even at highest sensitivity (Figure 2). This was probably because ESR particularly detects iron compounds rather 


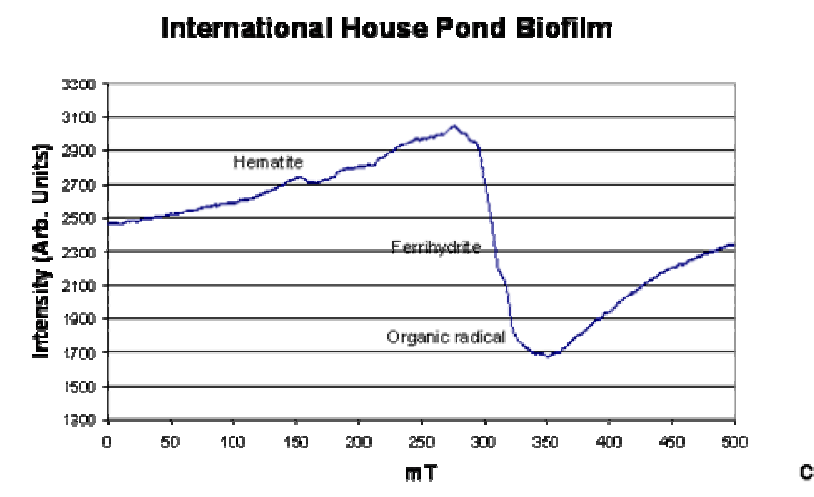

Kanazawa Microbial Mat

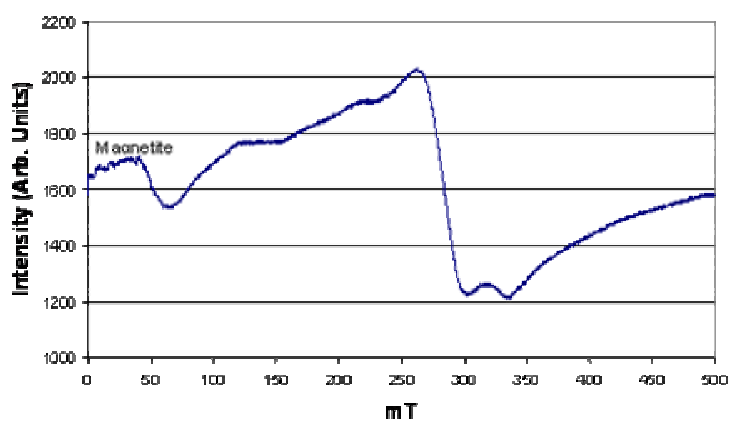

Figure 3c. Biofilm, 11 days growth.

Figure 3d. Biofilm, 2 years storage.

than the bacteria directly and the iron compounds had not had time to accumulate on the free-floating bacteria.

The first biofilm samples taken in New Zealand were airmailed to the laboratory in Osaka for ESR spectrometry (Figure 3a). In spite of this lag which might have reduced the intensity of visible ESR peaks, strong broad peaks were visible, mainly around $\mathrm{g}=2.13$ and often $\mathrm{g}=4.3$ in a fairly constant proportion. It would be usual in the ESR field to identify the $\mathrm{g}=2.13$ peak as pseudo-amorphous ferric oxyhydroxide, or ferrihydrite which has a very broad peak due to many chemically similar Fe sites. In neither case can the broadness be due to a single compound such as a macromolecule, with many parts of it clustering round a central Fe atom, because the broadness would require hundreds of parts, which would be impossible because of overcrowding. Potentially this large peak could also be due to $\mathrm{Mn}^{+4}$ (as manganese dioxide) which can have a g-value as high as 2.13 (Kakazey et al. 2003) and a similarly broad peak, but the 2.13 g-value was quite unusual, and we conclude this identification is quite unlikely.

A comparison of analyses for total $\mathrm{Fe}$ and $\mathrm{Fe}$ detectable by ESR suggested only about $15 \%$ was being detected by ESR. This meant the undetected majority of Fe was in amorphous chemical sites.
We identify the peak as Fe-associated because firstly there is generally thirty times as much iron as manganese in most environmental niches such as river water, both being almost entirely attached to particulate matter (Reid et al. 1999), so the peak is probably $\mathrm{Fe}$ rather than $\mathrm{Mn}$. Secondly the correlation of peaks at $\mathrm{g}=4.3$ and $\mathrm{g}=2.13$ argues for an identification as Fe. Thirdly the iron support clips for the plastic sheet rusted surprisingly fast underwater to ferrihydrite and created a localised yellow-brown rust stain whose most prominent ESR peak (in an intense ESR spectrum) was similarly at $\mathrm{g}=2.12$ and showed the peak at $\mathrm{g}=4.3$ in the usual proportion, and the usual intensity of the organic radical. Rust is a mixture of compounds in the hydrated ferric oxide-hydroxide range: goethite, ferrihydrite and lepidocrocite, and is conveniently called "ferrihydrite". An alternative name for the same class of compounds is "limonite". We provisionally call the peak at $\mathrm{g}=2.13$ "ferrihydrite" and that at $\mathrm{g}=4.3$ "hematite" without completely excluding other possibilities, though they seem unlikely. Powdered specimens of magnetite and hematite gave ESR peaks similar to those in the biofilm spectra.

Although at this preliminary stage detailed identification of the bacteria/algae/fungi comprising the film was not attempted, the bacteria probably contain significant amounts of Fe-oxidising bacteria capable of converting $\mathrm{Fe}^{+2}$ to $\mathrm{Fe}^{+3}$. These were a minority in the majority Flavobacteria of the Minoh River. After detailed identification it would be possible to determine what percentage of the total biomass is being detected.

Good ESR spectra (Figure 3a) were obtained from biofilms which were only 1 day old, unweighably light, and invisible to the eye. A sharper component overlays a broader one and a trace of hematite at $\mathrm{g}=4.3$ is visible in spite of spectral noise. The sharp ferrihydrite peak is much more intense than the noise and argues that ESR could detect considerably smaller biofilm amounts than those present at 1 day.

No consistent differences were noted between New Zealand and Japanese biofilms.

In Figure $3 \mathrm{~b}$, the ferrihydrite peak is much sharper than in films allowed to accumulate longer (Figure 3c). This probably means that initially there are few chemical environments for the $\mathrm{Fe}$, but as the film becomes more complex the number of environments multiplies.

The Kanazawa biofilm ESR spectrum (Figure 3d), contained a peak ascribed to magnetite $(\mathrm{g}=9)$. It is not easy to give other interpretations for the peak. The amount of magnetite was very small, and the sample was not attracted to a strong permanent magnet. The angular distribution of the spectrum will be the subject of an independent paper.

Figure $3 \mathrm{a}$, Figure $3 \mathrm{~b}$ and Figure $3 \mathrm{c}$, Figure $3 \mathrm{~d}$ are fairly typical of the evolution of ESR biofilm spectra with time. 
Minoh R. Park Biofilm Time Series

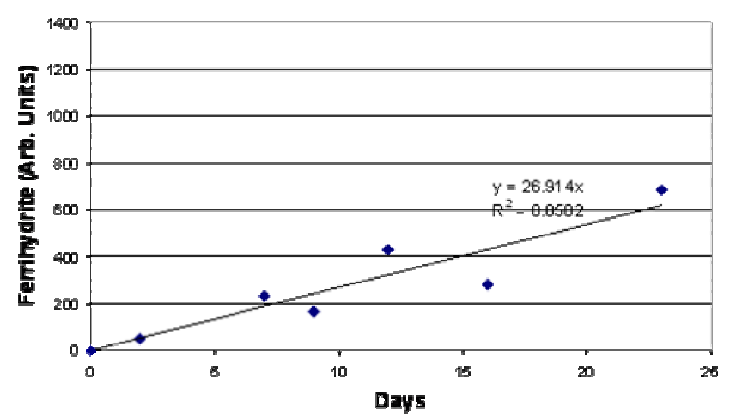

a

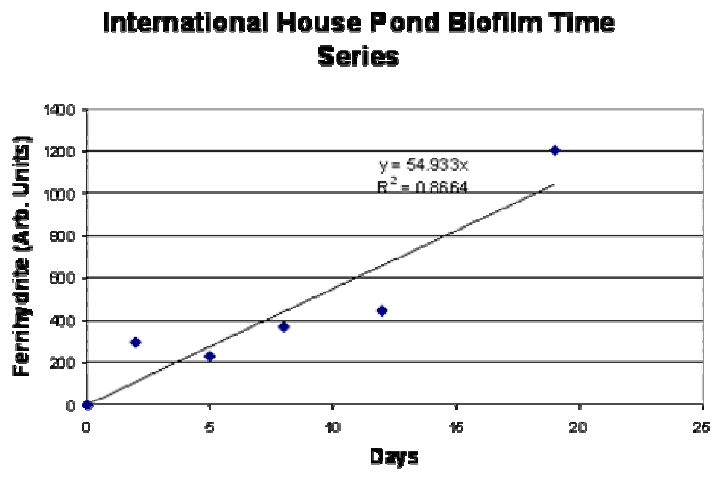

b

Figure $4 \mathrm{a}$ and $4 \mathrm{~b}$. Biofilm time-series.

The substrate (polypropylene or PTFE) seemed to make little consistent difference to spectrum shape or intensity. For three comparison sets of films from Tributary, Minoh R., International House Pond, and Park, Minoh R, the PP/PTFE ratio was $1.5 \pm 1.5$ and consistent with being 1.0 , i.e. there was no difference. It therefore seemed there had been little point in finding slightly hydrophilic plastic surfaces, however they may have discouraged exfoliation.

All spectra showed a small organic radical peak at about $\mathrm{g}=2.004$ to $\mathrm{g}=2.005$, which corresponds to the already known common bacterial decay products at 2.0037 and 2.0055 (Swartz et al. 1972). This was consistently observed, after airmail and after 18 months storage in the laboratory. In earlier films it tended to be more prominent relative to the "ferrihydrite".

As the biofilm accumulated over days, it became slowly visible on the plastic as a grey layer, (light brown when scraped off) but the colour was only obviously rusty on specimens allowed to accumulate growing biofilm for several months. Ferrihydrite is rust coloured so the amounts in young biofilms must be very small and calculation by comparison with a $\mathrm{Mn}^{+2}$ standard shows they must be fractions of a microgram, not more than a few percent of total dry weight. This shows that the method is very sensitive for Fe detection.
Biofilm time series were run in a New Zealand stream, Minoh R. and International House Pond, i.e. see results for Minoh R. City site, in Figure 4. The literature showed that biofilms eventually exfoliate in 9-24 days (Morikawa, 1988; Tokunaga and Morikawa, 2000; Rice et al. 2003). We did not see clear exfoliation, perhaps because the biofilms were not old enough. The results for all sites showed a general increase of ferrihydrite with time, and exfoliation seems unlikely at less than about 20 days.

The top points in Figure 4a and Figure 4b corresponded to dry-weight accumulations of $0.12 \mathrm{mg} / \mathrm{cm}^{2}$ and $0.49 \mathrm{mg} / \mathrm{cm}^{2}$ of plastic surface (on one side only) for the time periods shown. This 1:4 ratio is total biomass plus products, not solely ferrihydrite. However the corresponding ratio of ferrihydrite for the top points in the two figures is about $1: 2$, which is significantly less, and shows change in the relative biotic composition at the two sites. There is significant scatter in Figure 4a and Figure 4b and not enough points are available for a good statistical comparison of rates, which just fail to reach the statistical significance to show differences. However comparing total ferrihydrite for the longest accumulation period, the clearwater GNS site (not shown) was very similar to the Minoh R. Park site sample. This shows that ESR can detect differences in ferrihydrite accumulation rates through comparison of the highest points on the figures. Better time series results would require more data points.

A specimen of mature biofilm scraped from a rock gave an ESR spectrum quite similar to that of a mature biofilm on plastic. This means the natural $\mathrm{Fe}$-metabolising bacteria are not greatly disturbed by differences in substrate, and are common in many biofilms.

Gamma irradiation did not change biofilm spectra, though it commonly creates new ESR peaks in solid samples. From previous work (Bartoll and Tani, 1998) changes in hematite and magnetite should not occur during gamma irradiation, and are unlikely in near-amorphous ferrihydrite. The results were therefore about what we expected.

Low temperatures (to $-150^{\circ} \mathrm{C}$ ) created new ESR peaks from $\mathrm{g}=1.85$ to $\mathrm{g}=2.04$, but they were small compared with the large ferrihydrite peak and disappeared on return to ambient temperature. This showed that the changes were reversible, and not due to cell breakage on freezing and thawing. They must be reversible changes in frozen cell geometries on a macro scale, but we cannot yet identify what they may be.

This work raised the question how far Fe-bacteria contribute to rusting processes in air, rather than under water. ESR Examination of rust flakes showed in one case peaks at $\mathrm{g}=2.0$ and 4.3 and in a second, 4.3 only, consistent with known aerial weathering processes (Brown et al. 1998) but in neither case organic radicals. This suggests that at Osaka bacteria do not contribute greatly to the oxidation of iron in air. 


\section{DISCUSSION}

The ESR technique cannot be used for biofilms directly on metal, which is a limitation.

Using fluorescent methods involving acridine orange one can detect the presence of a biofilm within $2 \mathrm{hrs}$ (Personal Comm. Morikawa). Via ESR, biofilms were detected after an exposure of one day, but the true sensitivity is much better. The film area used in the spectrometer could be easily increased by several times, and the one-day spectrum in Figure 3a is a strong signal; a much weaker one could be easily detected. This depends on the accumulation being linear as figures $4 \mathrm{a}$ and $4 \mathrm{~b}$ suggest. Therefore ESR is at least competitive in sensitivity with fluorescent methods. Calculation suggests that detection of $0.5 \%$ of a single cell weight in the form of $\mathrm{Fe}$ could be detectable. This would need special signal processing, but single-cell sensitivity seems possible.

It is not clear how sensitive the method is for biofilms in general. The bacterial decay signal at $\mathrm{g}=2.004$ to $\mathrm{g}=2.005$ was much smaller than the ferrihydrite signal, but if it corresponds to a general presence of bacteria, not just Femetabolising bacteria, $0.1 \mathrm{mg} \mathrm{cm}^{-2}$ of bacterial dry mass or less can be detected. A calculation similar to that in the last paragraph suggests that a few tens of cells could be detectable.

The detection of Fe-metabolising bacteria by ESR relies chiefly on the detection of the iron compounds they excrete. These accumulate and increase outside the bacteria, even when the number of bacteria is constant, which is why the method is sensitive, but the quantity of iron compounds is a measure of the integrated metabolic activity rather than the biomass. Thus if a single cell produces oxidised iron compounds for a few days it could be detected easier than producing iron compounds at the same rate for only a few hours. In both cases only a single cell would be metabolising.

The literature on Fe-metabolising bacteria mainly deals with species which reduce $\mathrm{Fe}^{3+}$ to $\mathrm{Fe}^{2+}$ (Coates et al. 2001) but species which oxidise $\mathrm{Fe}^{+2}$ are well known (Tazaki et al. 2002). In some cases both have been reported on opposite sides of the same film (Brown et al. 1994). The predominant compound detected in the present films was ferrihydrite, which is an oxidised form of Fe.

In a survey of local Fe-bacteria products it was noted that hematite was rare except for samples which had been heated for a long time (Tazaki et al. 2002). The peak interpreted in our samples as hematite is usually found not in aqueous biota, but in drier conditions and higher temperatures (after fires, Bartoll and Tani, 1998). It is also an oxidised form of $\mathrm{Fe}$, without water, unlike ferrihydrite, and is common in our biofilms. Hematite is bacterially produced by oxidation of $\mathrm{Fe}^{2+}$ but only at $80^{\circ} \mathrm{C}$ (Brown et al. 1998). These latter bacteria multiplied at alkaline $\mathrm{pH}$, quite different from our neutral conditions and low temperatures. The lack of reports about hematite in biota at ambient temperatures may mean that ESR is detecting with high sensitivity a very minor product in the biofilms.

The previously referenced survey (Tazaki et al. 2002) did not note any magnetite, and again ESR probably detected it only because of its high sensitivity. The magnetite peak in the ESR spectrum was small and obscure and only seen in one sample, but is normally only found in hot spring samples (Zhang et al. 1998). Some $\mathrm{Fe}^{2+}$ as well as $\mathrm{Fe}^{3+}$ is incorporated in magnetite which means it is probably formed from previously oxidised $\mathrm{Fe}$ by further reduction which seems inefficient. Perhaps this sample, enclosed for two years, exhausted its oxic environment and Fe-reducing bacteria were able to multiply and produce magnetite.

Some studies have shown that the application of an electric charge to metal inserted in water can strongly improve the biofilm formation and this could be useful in future studies. We mentioned earlier the difficulty of using metal films in ESR studies, however it could be possible to use a very thin film of carbon deposited on a plastic film. Preliminary work in this laboratory suggests that any ESR interferences from the film are small. Anti-static electronic bags may also be worth investigating. Plastic electrets are an attractive idea, but the permanent electric field is likely to interfere with ESR analysis.

Another material found to contribute very low ESR background was fibreglass "wire". This physically strong material could be used directly suspended across a stream and analysed piece by piece afterwards, to give the rates of accumulation simultaneously at many different points, which should be inversely proportional to water current velocity.

In no spectrum was $\mathrm{Mn}^{+2}$ observed. This corresponds to other work (Robbins et al. 1999) who using orthotoluidine as a test, found not reduced, but oxidised Mn (manganese dioxide) associated with all components of biofilms including the orange $\mathrm{Fe}$ oxyhydroxide zone.

\section{CONCLUDING REMARKS}

This method seems very good to analyse biofilms containing Fe-bacteria. However the processes in biofilms from the environment are complex and laboratory studies under carefully controlled conditions may give results which are simpler to interpret. The results in this study seemed mainly to correspond with the activity of Feoxidizing bacteria. Because of the high sensitivity, it is possible that some of the results obtained correspond only to quite minor metabolic pathways.

This method should be very sensitive for Mn bacteria in biofilms under reducing conditions and the characteristic $\mathrm{Mn}^{+2}$ ESR sextet signal would be prominent. There should be no interference from Fe provided the conditions reduce 
$\mathrm{Fe}^{3+}$ to $\mathrm{Fe}^{2+}$. Probably a sample would show peaks due to $\mathrm{Mn}^{2+}$ or $\mathrm{Fe}^{2+}$ but seldom both at the same time. In oxidising conditions, the ESR peaks of $\mathrm{Mn}^{4+}$ and $\mathrm{Fe}^{3+}$ could interfere when there was an unusual amount of Mn present.

\section{ACKNOWLEDGMENTS}

We thank Professor Morikawa for helpful discussions. N.E.W. wishes to thank the Japanese Society for the Promotion of Science for a Senior Fellowship, and acknowledge remarkable hospitality from Prof. M. Ikeya, all in his department, and those at Kanazawa University. Thanks to the Institute of Scientific and Industrial Research, Osaka University for gamma irradiations.

\section{REFERENCES}

ARAYA, R.; YAMAGUCHI, N.; TANI, K. and NASU, A. Change in the bacterial community of natural river biofilm during biodegradation of culture-derived compounds determined by denaturing gradient gel electrophoresis. Journal of Health Sciences, 2003, vol. 49, no. 5, p. 379385.

BARTOLL, J. and TANI, A. Thermal history of archaeological objects, studied by electron spin resonance. Naturwissenschaften, 1998, vol. 85, no. 10, p. 474-481.

BROWN, D.A.; SAWICKI, J.A. and SHERRIFF, B.L. Alteration of microbially precipitated iron oxides and hydroxides. American Mineralogist, 1998, vol. 83, no. 11, p. 1419-1425.

BROWN, D.A.; KAMINENI, D.C.; SAWICKI, J.A. and BEVERIDGE, T.J. Minerals associated with biofilms occurring on exposed rock in a granitic underground research laboratory. Applied Environmental Microbiology, 1994, vol. 60, no. 9, p. 3182-3191.

COATES, J.D.; BHUPATHIRAJU, V.K.; ACHENBACH, L.A.; MCINERNEY, M.J. and LOVLEY, D.R. Geobacterhydrogenophilus, Geobacterchapellei and Geobactergrbiciae, three new, strictly anaerobic dissimilatory $\mathrm{Fe}$ (III)-reducers. International Journal of Systemic and Evolutionary Microbiology, 2001, vol. 51, p. 581-588.

KAKAZEY, M.; IVANOVA, N.; BOLDUREV, Y.; IVANOV, S.; SOKOLSKY, G. and GONZALEZRODRIGUEZ, V.M. Electron paramagnetic resonance in $\mathrm{MnO}_{2}$ powders and comparative estimation of electric characteristics of power sources based on them in the $\mathrm{MnO}_{2}-\mathrm{Zn}$ system. Journal of Power Sources, 2003, vol. 114 ,no. 1 , p. $170-175$.

KENZAKA, T.; YAMAGUCHI, N.; TANI, K. and NASU, M. Flavobacterium in rRNA-targeted fluorescent in situ hybridization analysis of bacterial community structure in river water. Microbiology, 1998, vol. 144, no. 8, p. $2085-$
2093.

MORIKAWA, K. Differences in plating efficiency of bacteria from river epilithon sampled from upper and lower surfaces of artificial substrata. Microbial Ecology, 1988, vol. 15 , no. 2 , p. $217-228$.

OKABE, S.; MATSUDA, T.; SATOH, H.; ITOH, T. and WATANABE, Y. Sulfate reduction and sulfide oxidation in aerobic mixed population biofilms. Water Science Technology, 1997, vol. 37, no. 4-5, p. 131-138.

REID, M.R.; KIM, J. P. and HUNTER, K.A. Trace metal and major ion composition of Lake Hayes and Manapouri. Journal of the Royal Society of New Zealand, 1999, vol. 29, no. 3, p. 245-255.

RICE, A.R.; HAMILTON, M.A. and CAMPER, A.K. Movement, replication, and emigration rates of individual bacteria in a biofilm. Microbial Ecology, 2003, vol. 45, no. 2, p. 163-172.

ROBBINS, E.I.; CORLEY, T.L. and CONKLIN, M.H.Manganese removal by the epilithic microbial consortium at Pinal Creek near Globe, Arizona. In: MORGANWALP, D.W. and BUXTON, H.T. eds. US Geological Service Toxic Substances Hydrology Program, 1999, vol. 1, p. 247-258, Reston, Virginia, USA.

SWARTZ, H.M.; BOLTON, J.R. and BORG, D.C.Biological applications of Electron Spin Resonance. New York, Wiley-Interscience, 1972, 569 p. ISBN 0471838705.

TAYLOR, G.T.; ZHENG, D.; LEE, M.; TROY, P.J.; GYANANATH, G. and SHARMA, S.K. Influence of surface properties on accumulation of conditioning films and marine bacteria on substrata exposed to oligotrophic waters. Biofouling, 1997, vol. 11, no. 1, p. 31-57.

TAZAKI, K.; ASADA, R. and IKEDA,Y. Quick occurrence of Fe-rich biofilms on the water surface. Nendo Kagaku, 2002, vol. 42, no. 1, p. 21-36.

TOKUNAGA, M. and MORIKAWA, K. Changes in biomass along biofilm formation in riverbeds with special reference to artificial substrata submerged in the Tamagawa River. Japanese Journal of Limnology, 2000, vol. 61, p. 147-154.

YAMAGUCHI, N.; OHMORI, H.; WELIKALA, N. and NASU, M. Biodegradation of chemical compounds in a newly developed modified river die-away test. Japanese Journal of Toxicology and Environmental Health, 1997, vol. 43, no. 4, p. 209-214.

YOKOMAKU, D.; YAMAGUCHI, N. and NASU, M. Improved direct viable count procedure for quantitative estimation of bacterial viability in freshwater environments. 
Whitehead, N. E. et al.

Applied and Environmental Microbiology, 2000, vol. 66, p. 5544-5548.

ZHANG, C.; VALI, H.; ROMANEK, C.S.and PHELPS, T.J. Formation of single domain magnetite by a thermophilic iron-reducing bacterium. American Mineralogist, 1998, vol. 83, no. 11, p. 1409-1418. 